\title{
Muscle Endurance Evaluation with the Sorensen Test and Correlation with Demographics and the Baecke Leisure- Time Sport Activity Index in Healthy Young Adults
}

\author{
Koumantakis GA ${ }^{1,2}$, Pallis $\mathrm{E}^{2}$, Mantzaris $\mathrm{A}^{2}$, Drakatos $\mathrm{A}^{2}$, Vlantis $\mathrm{Z}^{2}$ \\ ${ }^{1} 401$ General Army Hospital of Athens, Physiotherapy Department, Pan.Kanellopoulou1 , Athens, Greece. \\ ${ }^{2}$ Metropolitan College, Health Sciences Faculty, School of Physiotherapy Athens, Greece - Affiliated Institution with Queen Margaret \\ University, Edinburgh, UK.
}

Received: April 16, 2018; Accepted: April 25, 2018; Published: May 02, 2018

*Corresponding author: GA Koumantakis, Metropolitan College, Health Sciences Faculty, School of Physiotherapy, 74 Sorou Str., 15125, Marousi, Athens, Greece, Tel: +302106199891;E-mail: gkoymantakis@metropolitan.edu.gr

\begin{abstract}
Background: Endurance testing of the paraspinaland hip muscles is important for the prediction and prevention of back pain. Timed endurance determination of posterior chain muscles with the Sorensen test and correlations withanthropometry and leisure time sport activity in a mixedgender population of healthy participants were the primary objectives of this study.

Methods: 34 healthy young adults (16 women), with a mean age of 23.85 years participated in this study. Timed measurement of fatigue of the posterior chain muscles, in an unsupported isometric trunk-holding contraction in the horizontal position, secured with three canvas straps onto a therapy bed (Sorensen test) was performed to complete exhaustion. Subjects also completed the Baecke Habitual Physical Activity-Sport Index subscale. Between-gender differences were determined and correlations between anthropometry, leisuretime sport activity and Sorensen test values were assessed.

Results: There were between gender differences identified for Sorensen tes values, however these were not statistically significant (mean difference=31.4 s). Sorensen test values correlated significantly with the Baecke Sport Index ( $\mathrm{r}=0.78$, $\mathrm{p}<0.01)$. There were also significant negative correlations between Sorensen test values $(\mathrm{r}=-0.40, \mathrm{p}=0.02)$ and the Baecke Sport Index $(\mathrm{r}=-0.35, \mathrm{p}=0.04)$ with BMI.

Conclusions: Leisure-time sport activity is associated with the posterior chain muscles isometric endurance performance in the Sorensen test in a group of participants without low back pain, of various sporting involvement. This finding highlights the significant role of leisure time sport activity on hip and paraspinal muscle endurance levels, possibly acting preventively in future firsttime back pain development.
\end{abstract}

Keywords: Sorensen test; assessment; isometric endurance; back pain prevention

\section{Introduction}

Non-specific low back pain remains the most common and costly health conditionrequiring rehabilitation, with $28.4 \%$ of adults older than 18 years reporting back pain in the previous 3 months and an annual cost of $\$ 100-200$ billion per year for its management [1]. Classification schemes are continuously developed to describe the course and etiology of LBP and especially its onset at an early age, from adolescence to young adulthood [2], with the aim to establish preventive strategies for this musculoskeletal condition.

Intuitively, physical activity is an important preventive measure against deconditioning and associated musculoskeletal pain states [3]. Youth physical fitness recommendations in the US suggest the optimal daily exercise levels for children and adolescents amount to 60 minutes or more of daily exercise [4]. Back pain prevention strategies may need to be employed even in schoolchildren and adolescents in order to contain some of the reasons contributing to back pain $[5,6]$.

However, not all sports-specific interventions seem to be acting preventively as a recent cross-sectional study in Finnish adolescents has shown [7]. Similarly, sports or physical activity in leisure time was not a significant predictor in another recent study of several factors associated with the 1-month spinal pain prevalence in Belgian adolescents [8]. Along the same principles, a recent systematic review of 21 randomized-controlled trials (RCTs), identified low-to-moderate quality evidence of short and long-term benefits of several trunk exercise prevention strategies combined with education on biomechanics/lifting techniques in participants without previous back pain [9].

Associations between leisure time physical activity or inactivity and back muscle endurance have been previously identified in healthy populations of adolescents [6], which may act as a precursor to posture-related LBP development [10, 11]. However, the same research group suggested that physical factors as endurance and flexibility may not be either the sole or the most significant determinants of LBP development in adolescents [12]. Apart from the physical, other factors can predict the development and maintenance of LBP, however the preventive component of exercise seems important $[13,14]$. It may either be that physical fitness is not equally important to every subject or that different exercises can target different mechanical deficits and some individualized assessment and exercise prescription, either for primary or secondary prevention 
may need to be employed [15], or it may relate to adherence to exercise [16], or even that the level of physical fitness required to have a preventive effect is related to the physical demands of the actual task it serves.

Adequate levels of paraspinal muscle endurance, assessed with the maintenance of the horizontal trunk posture with the trunk unsupported in the prone position (Sorensen test), are considered preventive against the development of mechanical LBP [17-20]. The Sorensen test evaluates the static endurance of the trunk extensor muscles and is considered the tool of reference for evaluating muscle performance in patients with low back pain, most notably before and after rehabilitation programs [21]. This test has also been shown to activate the gluteal and hamstring muscles as well as the deep abdominal muscles, therefore it may be representative of a particular muscle synergy being tested with this method of assessment [22].

Psychological readiness to perform the test as well as pain on the other hand may be limiting factors for participants to reach their true level of complete exhaustion. Therefore, this test can be more reliably implemented in LBP populations after pain levels have subsided, to diagnose remaining muscle deficits that may need addressing in order to avoid LBP recurrence[21]. Indeed, some of the physical risk factors can be more clearly identified in first-time LBP development populations, such as posterior chain muscle fatigue $[5-6,17,23]$, than in the chronic stage, where the outcome of muscle performance is more likely to be confounded by pain and psychological factors [24]. Interestingly enough, a recent study has demonstrated also a link between isometric flexor and extensor trunk muscle performance with better intervertebral disc metabolism and hydration in healthy participants [25].

Therefore, the main purpose of this study was to obtain a measure of isometric posterior chain muscle fatigue via application of the Sorensen test in a group of young healthy adults, and evaluatethe level of correlation between participants' levels of sporting activity and their performance on the Sorensen test.

\section{Methods}

\section{Subjects}

Thirty-four healthy young adults volunteered to participate in this study. They comprised a convenience sample of 16 female and 18 male college students. The subjects were not randomly chosen. Subjects were invited to participate either via e-mail or via notice-board notifications.The mean (SD) demographic characteristics of all participants were: age 23.85(2.56) years, height 1.71(0.08) $\mathrm{m}$, body mass $69.47(13.56) \mathrm{Kg}$ and BMI $23.46(2.95) \mathrm{kg} / \mathrm{m}^{2}$.The criteria for participation were not to have had any previous LBP episode, any serious injury or not suffering from any kind of disability. Additionally, pain during the Sorensen test was also an exclusion criterion, as well as menstruation for female participants, to ascertain there were no confounding effects of current pain presence on the experimental procedures. All participants were advised to wear athletic outfit during testing. All subjects signed a written informed consent, presenting the inclusion and exclusion criteria as well as the aims and purposes of the study prior to their participation. The study protocol was approved by the Ethics Committee of Metropolitan College. All rights of participants were protected at all times, according to the Declaration of Helsinki.

\section{Experimental Procedures}

Subjects were required to fill in a questionnaire with their demographic data as well as the Sport Index subscale of the Baecke's Habitual Physical Activity Questionnaire [26]. The whole questionnaire consists of 16 questions and questions 9-12 comprise the Sport Index. Each question receives a score between 1-5 and the scores for questions 9-12 are added and then divided by 4 , according to a formula provided [26]. The Baecke questionnaire has been validated further in adult male [27] and female [28] populations.

Immediately after a brief warm-up session of trunk full ROM activity followed, by repeating 3 movements maintained to end of range for $2 \mathrm{~s}$ in 6 directions of movement. Then the Sorensen test was administered, according to its original description [17]. Each subject had to lie prone on an examination table. The lower body was securely stabilized on the table with three straps located around their pelvis, knees and ankles. A pillow was placed below the ankles so that the participants wouldn't feel any pain from the straps. The upper body was hanging off the examination table from the upper edge of the iliac crests that touch the edge of the table. A chair was placed under the patient's upper body, which was in the air during the procedure, for the participant to hold onto before the start of the test, so as to make the participant feel secure and confident. When the test begun, subjects had to let go of the chair and fold their arms onto their chest, and were asked to isometrically maintain the upper body in a horizontal position. The time during which the subject maintained the upper body in a straight and horizontal position was recorded to the nearest second by an electronic chronometer. Subjects were continuously monitored by two examiners. In cases of subjects that experienced no difficulty in holding the test position, the test was stopped after $240 \mathrm{~s}$. Reasons to discontinue the procedure before the first $240 \mathrm{~s}$ were if the subjects' trunk was beginning to slope downwards by visual estimation or if they experienced muscle spasms for longer than 5 seconds. The reliability of the test has been extensively reported in previous studies [21, 29]. It has to be emphasized that this test assesses the endurance not

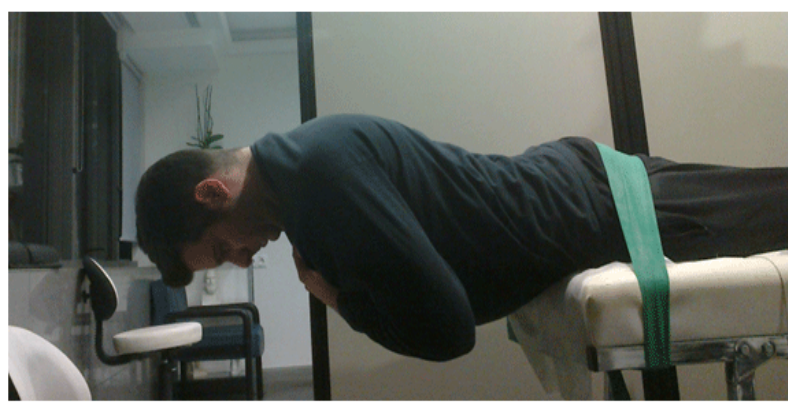

Figure 1: Testing position for the Sorensen test. 


\section{Adults}

only of the paraspinal muscles but also the gluteal and hamstring muscles simultaneously [17, 21-22], however without any persistent adverse effects such as pain exacerbation reported after administering this test [21](Figure 1).

\section{Statistical Analysis}

All data (demographic, endurance times and leisure-time sport-activity levels) conformed to a normal distribution, examined with the Kolmogorov-Smirnov test. Therefore, between-gender comparisons of demographic, sport-activity and Sorensen endurance time characteristics were analyzed with the unrelated samples T-test (Table 1). Correlations between variables were performed for the whole cohort (Table 2) and for male and female participants separately, with the Pearson's product correlation coefficient. A sample size of 15 participants per correlation, for a level of correlation coefficient $r=0.70$, power of $85 \%$ and significance level $a=0.05$ for the correlation to be statistically significant from zero,was estimated via an online sample size calculator (http://www.sample-size.net/correlationsample-size/).

\section{Results}

The thirty-four subjects recruited completed all measurements, including the Sorensen test and the Sport Index of the Baecke Habitual Physical Activity Questionnaire without any reported problems in test delivery or missing data.

The characteristics of our participants (mean \pm SDs) are presented according to their gender in table 1.

A primary objective of our study was to assess whether there was a differential influence on the Sorensen test and the Sport Activity Index results based on gender. From analysis of our data with the unrelated samples t-test, there were no significant between-gender differences identified, apart from the height, weight and BMI of participants (Table 1).

Table 1: Between-gender differences for anthropometric data, Sorensen test values and Baecke Sport Index values, compared with unrelated samples t-test.

\begin{tabular}{|c|c|c|c|c|c|c|c|}
\hline & Gender & $\mathbf{N}$ & Mean & SD & Mean Difference & $\mathbf{t}$ & $\mathbf{p}$ \\
\hline \multirow{2}{*}{ Age (yrs) } & male & 18 & 24.05 & 3 & \multirow[t]{2}{*}{0.43} & \multirow[t]{2}{*}{0.48} & \multirow[t]{2}{*}{0.63} \\
\hline & female & 16 & 23.62 & 2.03 & & & \\
\hline \multirow{2}{*}{ Weight (kg) } & male & 18 & 81.11 & 6.95 & \multirow[t]{2}{*}{24.74} & \multirow[t]{2}{*}{13.67} & \multirow[t]{2}{*}{$0,000^{* * *}$} \\
\hline & female & 16 & 56.37 & 2.09 & & & \\
\hline \multirow{2}{*}{ Height (m) } & male & 18 & 1.77 & 0.06 & \multirow[t]{2}{*}{0.13} & \multirow[t]{2}{*}{6.46} & \multirow[t]{2}{*}{$0,000^{* * *}$} \\
\hline & female & 16 & 1.65 & 0.05 & & & \\
\hline \multirow{2}{*}{ BMI (kg/m2) } & male & 18 & 25.78 & 1.77 & \multirow[t]{2}{*}{4.93} & \multirow[t]{2}{*}{9.04} & \multirow[t]{2}{*}{$0,000^{* * *}$} \\
\hline & female & 16 & 20.84 & 1.35 & & & \\
\hline \multirow{2}{*}{ Sorensen (s) } & male & 18 & 124.72 & 44.84 & \multirow[t]{2}{*}{31.4} & \multirow[t]{2}{*}{1.8} & \multirow[t]{2}{*}{$0.07 \mathrm{~ns}$} \\
\hline & female & 16 & 156.12 & 55.46 & & & \\
\hline $\begin{array}{l}\text { BaeckeQ - Sport } \\
\text { Index }(0-5)\end{array}$ & male & 18 & 2.54 & 1.52 & 1.41 & 1.4 & $0.17 \mathrm{~ns}$ \\
\hline
\end{tabular}

Pearson's correlation coefficient analysis revealed that Sorensen test values correlated significantly with the Baecke Sport Index $(\mathrm{r}=0.78, \mathrm{p}<0.01)$ for the whole cohort (Graph 1). Separate between-gender analyses confirmed this significant relationship both for male $(\mathrm{r}=0.85, \mathrm{p}<0.01)$ and for female $(\mathrm{r}=0.71$, $\mathrm{p}<0.01$ ) participants (Graph 2). There were also significant negative correlations between both the Sorensen test values $(\mathrm{r}=-$ 0.40, $\mathrm{p}=0.02)$ and the Baecke Sport Index ( $\mathrm{r}=-0.35, \mathrm{p}=0.04)$ with BMI. Also, expected significant correlations were noted between height and weight, BMI and height and BMI and weight (Table 2).

\section{Discussion}

The main finding of this study was a highly significant correlation observed between leisure time sport activity and isometric fatigue levels of the posterior muscle chain in healthy participants of both genders. Poor back muscle extensorendurance is deemed an important risk factor for patients with low back pain (LBP), as several research studies have documented in the past[17-20]. Therefore, there seems to be a positive relationship

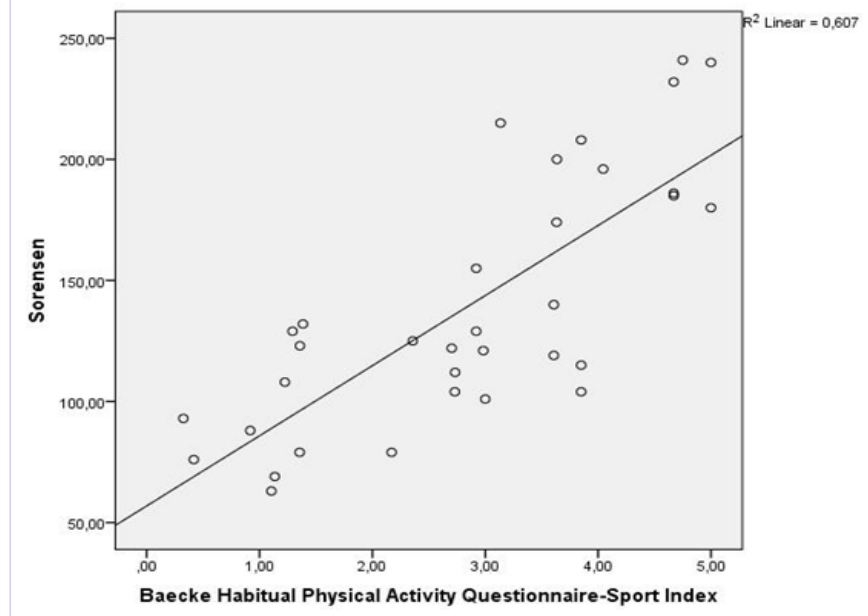

Graph1: Correlation between the time to fatigue Sorensen test values and the Baecke Habitual Physical Activity Questionnaire-Sport Index for all participants. 


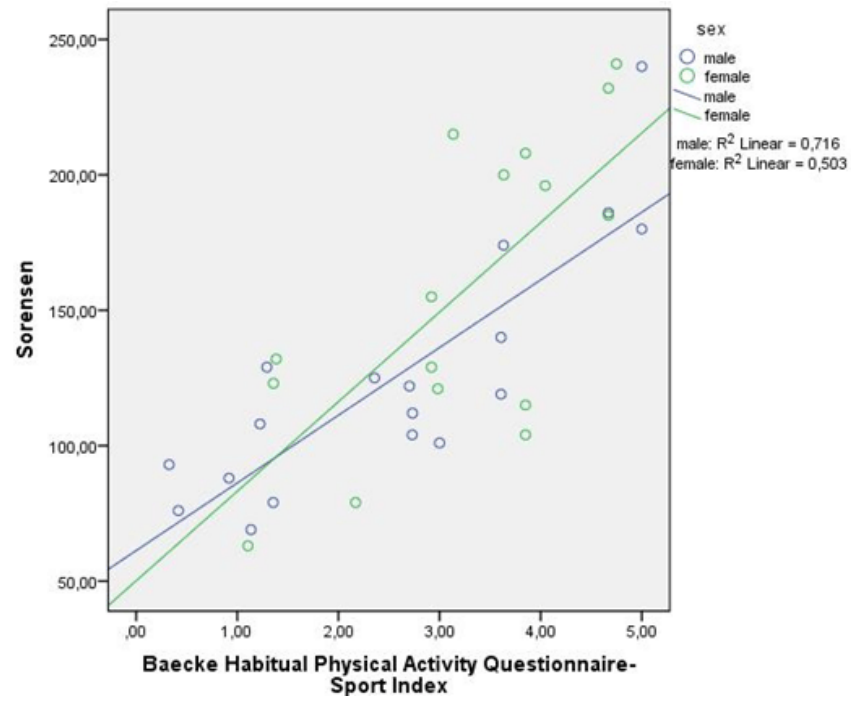

Graph 2: Correlation between the time to fatigue Sorensen test values and the Baecke Habitual Physical Activity Questionnaire-Sport Index separately for male and female participants.

between the frequency and intensity of exercise performed at leisure-time, as documented with the Baecke Sport Index and levels of muscle endurance as measured with the Sorensen test. This finding may lend support to the preventive role of exercise in contracting first-time back pain in young adolescents, as exercise seems to maintain the fatigue characteristics of the posterior chain muscles at a level that those muscles are able to support the lumbopelvic complex during movement as well as sustained postures within the appropriate margin of safety. Similar $[6,14]$ as well as opposite [8-9] findings to ours have also been reported. Possible differences in the outcome assessments between studies and also between the populations characteristics, sample sizes as well as the number of variables tested may account for such discrepancies [30].

In addition, there was a significant influence of BMI on the Sorensen test results from the negative significant correlation reported, as there was also a similar level negative correlation of BMI with the Baecke leisure time Sport Activity Index, therefore it seems that subjects of higher BMI tend to have decreased levels of leisure time sport activity and perform less well on the isometric Sorensen fatigue test. However, the possible confounding effect of BMI on the relationship between Sorensen test fatigue data and leisure time sport activity levels needs to be examined in a future, larger scale study. A similar effect of gender or age of participants on either of these variables was not established in our study, however a previous study with a larger sample-size has been able to demonstrate a significant effect of all 3 variables in the Sorensen endurance timed test [31].

A methodological issuethat occurredas testing of endurance progressed was that there seemed to be a difficulty in completely fixingsome of the volunteers onto the examination table with the 3 straps employed, as in some cases there seemed to be some loosening of the straps as time progressed. Additionally, the
Table 2: Correlations between Sorensen test values and anthropometric and habitual leisure-time physical activity data for the whole group of participants $(n=34)$.

\begin{tabular}{|c|c|c|c|c|c|c|}
\hline & & Age & Weight & Height & BMI & Sørensen \\
\hline Age & $\mathrm{r}$ & 1 & & & & \\
\hline \multirow{2}{*}{ Weight } & $r$ & 0.2 & \multirow{2}{*}{1} & & & \\
\hline & $\mathrm{p}$ & 0.26 & & & & \\
\hline \multirow{2}{*}{ Height } & $r$ & 0.11 & $0.83^{* *}$ & \multirow{2}{*}{1} & & \\
\hline & $\mathrm{p}$ & 0.52 & $<.01$ & & & \\
\hline \multirow{2}{*}{ BMI } & $r$ & 0.19 & $0.88^{* *}$ & $0.47^{* *}$ & \multirow{2}{*}{1} & \\
\hline & $\mathrm{p}$ & 0.28 & $<.01$ & $<.01$ & & \\
\hline \multirow{2}{*}{ Sorensen } & $\mathrm{r}$ & -0.17 & -0.27 & -0.05 & $-0.40^{*}$ & \multirow{2}{*}{1} \\
\hline & $\mathrm{p}$ & 0.33 & 0.12 & 0.76 & 0.02 & \\
\hline \multirow{2}{*}{$\begin{array}{c}\text { Baecke Q } \\
\text { SportIndex }\end{array}$} & $r$ & -0.23 & -0.22 & -0.01 & $-0.35^{*}$ & $0.78^{* *}$ \\
\hline & $\mathrm{p}$ & 0.19 & 0.2 & 0.93 & 0.04 & $<.01$ \\
\hline
\end{tabular}

evaluation could have taken place in two days rather than one, to have an extra session for familiarization purposes; however this was not possible due to the timescale of this study.

Also, in a future investigation the preventive role of particular types of exercises or sport activities could be examined. Finally, this study would have to be replicated in a larger sample of healthy participants of younger and older age groups, occupational settings and different loading exposures, to validate our findings further. Other variables possibly acting as first-time LBP development risk factors, such as postural [32] or flexibility [13] measurements or lifestyle and psychosocial factors [8] could be collected in parallel. Taking into account all the above suggestions, our results of increased posterior muscle chain endurance with increased levels of leisure time physical activity levels require further validation for the external validity of our findings to be ascertained in relation to other risk factors acting in parallel for first time back pain development, across a wider age scope and spine loading exposure situations.

\section{Conclusion}

This research study has demonstrated a highly significant association between leisure-time physical activity levels and the isometric endurance as examined with the Sorensen test. This finding, although it requires further validation, can provide some preliminary support in the maintenance of optimal posterior chain muscle endurance characteristics via frequent habitual sporting leisure-time activity.

\section{Acknowledgements}

This work was completed as a research project towards the fulfillment for a "BSc (Hons) Physiotherapy" degree at the Athens Metropolitan College Greece, an affiliated programme of Queen Margaret University, Edinburgh, UK. 


\section{Adults}

\section{Conflict of Interest}

The authors declare that there is no conflict of interest regarding the publication of this paper.

\section{References}

1. Ma VY, Chan L, Carruthers KJ. Incidence, prevalence, costs, and impact on disability of common conditions requiring rehabilitation in the United States: stroke, spinal cord injury, traumatic brain injury, multiple sclerosis, osteoarthritis, rheumatoid arthritis, limb loss, and back pain. Arch Phys Med Rehabil. 2014;95(5):986995.e1. Doi: 10.1016/j.apmr.2013.10.032

2. Coenen P, Smith A, Paananen M, O'Sullivan P, Beales D, Straker L. Trajectories of Low Back Pain From Adolescence to Young Adulthood. Arthritis Care Res (Hoboken). 2017;69(3):403-412. Doi: 10.1002/acr.22949

3. Smuck M, Kao MC, Brar N, Martinez-Ith A, Choi J, Tomkins-Lane CC. Does physical activity influence the relationship between low back pain and obesity? Spine J. 2014;14(2):209-216. Doi: 10.1016/j. spinee

4. Ganley KJ, Paterno MV, Miles C, Stout J, Brawner L, Girolami G, et al.Health-related fitness in children and adolescents. Pediatr Phys Ther. 2011;23(3):208-220. Doi: 10.1097/PEP.0b013e318227b3fc

5. Taylor JB, Goode AP, George SZ, Cook CE. Incidence and risk factors for first-time incident low back pain: a systematic review and meta-analysis. Spine J. 2014;14(10):2299-2319. Doi: 10.1016/j. spinee.2014.01.026

6. Smith AJ, O'Sullivan PB, Campbell A, Straker L. The relationship between back muscle endurance and physical, lifestyle, and psychological factors in adolescents. J Orthop Sports Phys Ther. 2010;40(8):517-523. Doi: 10.2519/jospt.2010.3369

7. Rossi M, Pasanen K, Kokko S, Alanko L, Heinonen OJ, Korpelainen $\mathrm{R}$, et al. Low back and neck and shoulder pain in members and non-members of adolescents' sports clubs: the Finnish Health Promoting Sports Club (FHPSC) study. BMC Musculoskelet Disord. 2016;17(1):263. Doi: 10.1186/s12891-016-1114-8

8. Dolphens M, Vansteelandt S, Cagnie B, Vleeming A, Nijs J, Vanderstraeten $G$, et al. Multivariable modeling of factors associated with spinal pain in young adolescence. Eur Spine J. 2016;25(9):2809-2821. Doi: 10.1007/s00586-016-4629-7

9. Steffens D, Maher CG, Pereira LS, Stevens ML, Oliveira VC, Chapple M, et al. Prevention of Low Back Pain: A Systematic Review and Meta-analysis. JAMA Intern Med. 2016;176(2):1-10. Doi: 10.1001/ jamainternmed.2015.7431

10. O'Sullivan PB, Mitchell T, Bulich P, Waller R, Holte J.The relationship beween posture and back muscle endurance in industrial workers with flexion-related low back pain. Man Ther. 2006;11(4):264-271. Doi: 10.1016/j.math.2005.04.004

11. Smith A, O'Sullivan P, Straker L. Classification of sagittal thoracolumbo-pelvic alignment of the adolescent spine in standing and its relationship to low back pain. Spine (Phila Pa 1976).
2008;33(19):2101-2107. Doi: 10.1097/BRS.0b013e31817ec3b0

12. Perry M, Straker L, O'Sullivan P, Smith A, Hands B. Fitness, motor competence, and body composition are weakly associated with adolescent back pain. J Orthop Sports Phys Ther. 2009;39(6):439449. Doi: 10.2519/jospt.2009.3011

13. Mikkelsson LO, Nupponen H, Kaprio J, Kautiainen H, Mikkelsson M, Kujala UM. Adolescent flexibility, endurance strength, and physical activity as predictors of adult tension neck, low back pain, and knee injury: a 25 year follow up study. Br J Sports Med. 2006;40(2):107-113. Doi: 10.1136/bjsm.2004.017350

14. Shiri R, Coggon D, Falah-Hassani K. Exercise for the Prevention of Low Back Pain: Systematic Review and Meta-Analysis of Controlled Trials. Am J Epidemiol. 2017. Doi: 10.1093/aje/kwx337

15. Fritz JM, Delitto A, Erhard RE. Comparison of classificationbased physical therapy with therapy based on clinical practice guidelines for patients with acute low back pain: a randomized clinical trial. Spine (Phila Pa 1976). 2003;28(13):1363-1371. Doi: 10.1097/01.BRS.0000067115.61673.FF

16. Van Dillen LR, Norton BJ, Sahrmann SA, Evanoff BA, Harris-Hayes M, Holtzman GW, et al. Efficacy of classification-specific treatment and adherence on outcomes in people with chronic low back pain. A one-year follow-up, prospective, randomized, controlled clinical trial. Man Ther. 2016;24:52-64. Doi: 10.1016/j.math.2016.04.003

17. Biering-Sorensen F. Physical measurements as risk indicators for low-back trouble over a one-year period. Spine (Phila Pa 1976). 1984;9(2):106-119. Doi: 10.1016/j.math.2016.04.003

18. Alaranta $H$, Luoto $S$, Heliovaara M, Hurri H. Static back endurance and the risk of low-back pain. Clin Biomech (Bristol, Avon). 1995;10(6):323-324.

19. Rissanen A, Heliovaara M, Alaranta H, Taimela S, Malkia E, Knekt $P$, et al. Does good trunk extensor performance protect against backrelated work disability? J Rehabil Med. 2002;34(2):62-66.

20. Johnson OE, Mbada CE, Akosile CO, Agbeja OA. Isometric endurance of the back extensors in school-aged adolescents with and without low back pain. J Back Musculoskelet Rehabil. 2009;22(4):205-211. Doi: 10.3233/BMR-2009-0235

21. Demoulin C, Vanderthommen M, Duysens C, Crielaard JM. Spinal muscle evaluation using the Sorensen test: a critical appraisal of the literature. Joint Bone Spine. 2006;73(1):43-50. Doi: 10.1016/j. jbspin.2004.08.002

22. Coorevits P, Danneels L, Cambier D, Ramon H, Vanderstraeten G. Assessment of the validity of the Biering-Sorensen test for measuring back muscle fatigue based on EMG median frequency characteristics of back and hip muscles. J Electromyogr Kinesiol. 2008;18(6):997-1005. Doi: 10.1016/j.jelekin.2007.10.012

23. Taanila HP, Suni JH, Pihlajamaki HK, Mattila VM, Ohrankammen O, Vuorinen P, et al. Predictors of low back pain in physically active conscripts with special emphasis on muscular fitness. Spine J. 2012;12(9):737-748. Doi: 10.1016/j.spinee.2012.01.006 


\section{Adults}

24. Huijnen IPJ, Verbunt JA, Wittink HM, Smeets RJEM. Physical performance measurement in chronic low back pain: measuring physical capacity or pain-related behaviour? European Journal of Physiotherapy. 2013;15(3):103-110. Doi: 10.3109/21679169.2013.830643

25. Quittner M, Rantalainen T, Ridgers ND, Trudel G, Sheikh A, Connell $D$, et al.Intervertebral disc status is associated with vertebral marrow adipose tissue and muscular endurance. Eur Spine J. 2018. Doi: 10.1007/s00586-018-5567-3

26. Baecke JA, Burema J, Frijters JE. A short questionnaire for the measurement of habitual physical activity in epidemiological studies. Am J Clin Nutr. 1982;36(5):936-942. Doi: 10.1093/ ajcn/36.5.936

27. Florindo AA, Latorre MdRDdO. Validation and reliability of the Baecke questionnaire for the evaluation of habitual physical activity in adult men. Revista Brasileira de Medicina do Esporte. 2003;9:129-35. Doi: 10.1590/S1517-86922003000300002

28. Ono R, Hirata S, Yamada M, Nishiyama T, Kurosaka M, Tamura Y. Reliability and validity of the Baecke physical activity questionnaire in adult women with hip disorders. BMC
Musculoskeletal Disorders. 2007;8:61. Doi: 10.1186/1471-24748-61

29. Latimer J, Maher CG, Refshauge K, Colaco I. The reliability and validity of the Biering-Sorensen test in asymptomatic subjects and subjects reporting current or previous nonspecific low back pain. Spine (Phila Pa 1976). 1999;24(20):2085-2089; discussion 90.

30. Bayraktar D, Ozyurek S, Genc A. The relationship between isometric trunk muscle endurance and physical activity related energy expenditure in healthy young adults. J Back Musculoskelet Rehabil. 2015;28(4):859-864. Doi: 10.3233/BMR-150618.

31. Kankaanpaa M, Laaksonen D, Taimela S, Kokko SM, Airaksinen O, Hanninen 0. Age, sex, and body mass index as determinants of back and hip extensor fatigue in the isometric Sorensen back endurance test. Arch Phys Med Rehabil. 1998;79(9):1069-1075.

32. Koumantakis GA, Nikoloudaki M, Thacheth S, Zagli K, Bitrou K, Nigritinos A, et al. Reliability and Validity Measurement of Sagittal Lumbosacral Quiet Standing Posture with a Smartphone Application in a Mixed Population of 183 College Students and Personnel. Adv Orthop. 2016;2016:3817270. Doi: $10.1155 / 2016 / 3817270$ 